\title{
Aprovechamiento del lactosuero como fuente de energía nutricional para minimizar el problema de contaminación ambiental
}

\section{Utilization of whey as a source of nutritional energy to minimize the problem of environmental pollution}

\author{
Aproveitamento do soro de leite coalhado como fonte \\ de energia nutricional para minimizar o problema de \\ contaminação ambiental
}

\author{
Álvaro Vicente Araujo Guerra', Lina María Monsalve Castro² \& Andrés Luciano Quintero Tovar ${ }^{3}$ \\ 'Medico Veterinario- Zootecnista, Magister en Reproducción Animal. 2Zootecnista, Magister en \\ Ciencias Agrarias. ${ }^{3 Z}$ Zootecnista, Magister en educación superior con énfasis en pedagogía. \\ 1, 2, ${ }^{3}$ Escuela de Ciencias Agrícolas Pecuarias y del Medio Ambiente, Universidad Nacional \\ Abierta y a Distancia, Valledupar, César, Colombia.
}

19alvaro.araujo@unad.edu.co, ${ }^{2}$ lina.monsalve@unad.edu.co, ${ }^{3}$ andres.quintero@unad.edu.co

\section{Resumen}

En este artículo se trata de conceptuar el potencial que tienen algunos desechos orgánicos que pueden ser utilizados como fuentes de energía, como es el caso del lactosuero, provenientes de la industria de productos lácteos, el cual genera un serio problema ambiental, debido a que afecta física y químicamente la estructura del suelo, lo que genera una disminución en el rendimiento de cultivos agrícolas y cuando se desecha en el agua, reduce la vida acuática al agotar el oxígeno disuelto; por lo tanto es necesaria la búsqueda de alternativas para disminuir el impacto causado por este tipo de residuo de la agroindustria, los cuales buscan el aprovechamiento de desechos orgánicos como fuentes de energía para que microrganismos seleccionados sinteticen los compuestos orgánicos y posteriormente se logre la obtención de masas microbianas que constituyen una gran fuente alimenticia de alto valor proteico, que solucionen el problema de alimentación humana, el cual también implica resolver el problema de las fuentes de proteínas para la alimentación animal y de igual manera se haría un aporte para minimizar el problema de contaminación ambiental.
Palabras clave: biomasa, contaminación, desechos orgánicos, lactosuero, proteína, residuos.

\section{Abstract}

This paper attempts to conceptualize the potential for some organic wastes to be used as energy sources. For example, whey produced by the dairy industry, which creates a serious environmental problem due to its effect on the physical and chemical structure of soils causing a decrease in crops yield and when disposed in water, reduces aquatic life by exhausting dissolved oxygen. Therefore, it is necessary to search for alternatives to lessen the impact caused by this type of agro-industrial waste. Such alternatives should also take advantage of the organic waste as an energy source that selected microorganisms can synthesize organic compounds within and subsequently obtain the microbial masses that constitute a major food source of high protein value. This alternative provides potential solutions to major issues such as human hunger, the lack of protein sources for animal feed and on the other hand, a reduction in environmental pollution.

Key-words: biomass, pollution, organic wastes whey, protein, residues 


\section{Resumo}

Este artigo trata-se de conceituar o potencial que alguns descartes orgânicos têm e que podem ser utilizados como fontes de energia, como é o caso do soro do leite coalhado proveniente da indústria de produtos lácteos, a qual gera um serio problema ambiental, ao fato de que esta atividade afeta as propriedades física e química da estrutura do solo, o que gera uma diminuição do rendimento de cultivos agrícolas e quando se despeja em água corrente, reduz a biodiversidade dos rios ao esgotar o oxigênio devolvido; por tanto é necessária a busca de alternativas para diminuir o impacto causado por este tipo de resíduo da agroindústria, os quais buscam o aproveitamento de descartes orgânicos como fontes de energia para que microorganismos selecionados sintetizem os compostos orgânicos e posteriormente obtenha-se uma grande massa microbiana que constituem uma grande fonte alimentícia de alto valor proteico, que solucionem o problema da alimentação humana, na qual também implica-se em resolver o problema das fontes de proteínas para a alimentação animal e de igual maneira faremos uma porta de entrada para minimizar o problema de contaminação ambiental.

Palavras chave: biomassa, contaminação, descartes orgânicos, soro de leite coalhado, proteína, resíduos.

\section{Introducción}

La industria de productos lácteos es uno de los sectores más importantes de la economía de muchos países y entorno a ella se ha desarrollado una tecnología completa y novedosa (Koutinas et al., 2009). Aproximadamente el $90 \%$ de la leche utilizada en la industria quesera es eliminada como lactosuero, el cual es uno de los subproductos más contaminantes que existen en la industria alimentaria. No usar el lactosuero como alimento es un gran desperdicio de nutrimentos ya que este contiene cerca del $55 \%$ del total de los ingredientes, entre los cuales se encuentran incluidos la lactosa, proteínas, materia grasa y sales minerales (Parra, 2009).

Al utilizar eficientemente este residuo se ha comprobado que 1.000 litros de lactosuero contienen más de $9 \mathrm{~kg}$ de proteína de alto valor biológico, 50 $\mathrm{kg}$ de lactosa y $3 \mathrm{~kg}$ de grasa de leche. Esto es equivalente a los requerimientos diarios de proteína de cerca de 130 personas y a los requerimientos diarios de energía de más de 100 personas (Inda, 2000), pero este residuo es desechado como efluente el cual crea un serio problema ambiental, debido a que afecta física y químicamente la estructura del suelo, lo cual genera una disminución en el rendimiento de cultivos agrícolas y cuando se desecha en el agua, reduce la vida acuática al agotar el oxígeno disuelto (Parra, 2009).

Por tal razón las entidades encargadas de vigilar el buen funcionamiento y aprovechamiento de los recursos naturales, han generado políticas (Ley 99 de 1993, Artículo 42), que buscan disminuir la contaminación de los cuerpos de agua por vertimientos líquidos a través del cobro de la tasa retributiva (DAMA, 2003). Sin embargo, si al lactosuero se le diera un uso sostenible que aproveche sus potencialidades, y genere ingresos adicionales a las empresas, se lograría disminuir su impacto contaminante de manera más eficaz, contribuyendo al logro de mejoras o modificaciones en el proceso productivo, para que sea más eficiente y provechoso, generando así mayores beneficios para la empresa y el ambiente.

Por otro lado el crecimiento poblacional, principalmente en los países en vía de desarrollo, es cada vez más abrumador, alcanzando durante esta primera década del siglo XXI entre 5 y 6 billones de personas (Chacón, 2004), con lo que las diferentes actividades agrícolas no pueden producir el suficiente alimento con alto valor nutritivo, por 
tal razón las necesidades alimentarias con fuentes proteicas se hacen cada vez más evidentes, tanto para la alimentación humana como para la alimentación animal, teniendo en cuenta que solucionar el problema de alimentación humana implica también resolver el problema de las fuentes de proteínas para la alimentación animal (Heden \& Enebo, 1969).

Por consiguiente, una alternativa podría ser la aplicación de procesos biotecnológicos, los cuales buscan el aprovechamiento de desechos orgánicos como fuentes de energía para que microorganismos seleccionados sinteticen los compuestos orgánicos y posteriormente se logre la obtención de masas microbianas que constituyen una gran fuente alimenticia de alto valor proteico (Almécija, 2007), de ahí que la utilización del hongo Geotrichum Candidum (Oospora lactis), Ilamado a menudo hongo de las lecheras, sería una buena opción para el aporte de productos de alto valor proteico (Ariza \& Franco, 2007), así mismo, el lactosuero es una excelente materia prima para obtener diferentes productos a nivel tecnológico o como medio de formulación en procesos fermentativos. A pesar del problema de contaminación que se genera, existen una infinidad de productos que se pueden obtener. Dentro de estos están ácidos orgánicos, productos de panadería, bebidas para deportistas, alcoholes, bebidas fermentadas, gomas, empaques biodegradables, sustancias inhibidoras de crecimiento, proteína unicelular, exopolisacáridos y concentrados proteicos, además, las proteínas del lactosuero tienen propiedades funcionales que permiten ser muy útiles en el área de los alimentos (Huertas, 2009), debido a que puede consumir la lactosa gracias a la generación de la enzima p- galactosidasa, además de asimilar el nitrógeno inorgánico produciendo en un tiempo corto una gran cantidad de biomasa con alta concentración de proteína (Zumbado et al., 2006), es por ello que se hacen esfuerzos considerables para explorar nuevas alternativas para la utilización de lactosuero y de esta forma se contribuya a la reducción de la contaminación ambiental.

\section{Tipos de Lactosuero y sus componentes}

Es un líquido de color verdoso amarillento obtenido a partir de la elaboración del queso durante la etapa de separación de la cuajada o fase micelar (Parra, 2009). También se puede definir como el líquido que luego de la precipitación de la caseína en la producción del queso, es separado de éste y cuya proporción es de aproximadamente nueve veces con respecto a la masa de queso obtenida (Panesar et al., 2007).

Existen varios tipos de lactosuero: el primero, denominado dulce, está basado en la coagulación por la renina a pH 6,5; el segundo, llamado ácido, resulta del proceso de fermentación o adición de ácidos orgánicos o ácidos minerales para coagular la caseína como en la elaboración de quesos frescos (Panesar et al., 2007). Según los datos bibliográficos de la composición nutricional de los lactosueros dulce y ácido, se observa que el primero presenta, ligeramente, mayores contenidos de lactosa y proteína (Tabla 1).

Tabla 1. Composición General del Lactosuero

\begin{tabular}{lcc}
\hline Constituyente & $\begin{array}{c}\text { Lactosuero } \\
\text { Dulce }(\mathbf{g} / \mathbf{L})\end{array}$ & $\begin{array}{c}\text { Lactosuero } \\
\text { Ácido }(\mathbf{g} / \mathbf{L})\end{array}$ \\
\hline Sólidos & $63,0-70,0$ & $63,0-70,0$ \\
Lactosa & $46,0-52,0$ & $44,0-46,0$ \\
\hline Proteína & $6,0-10,0$ & $6,0-8,0$ \\
Calcio & $0,4-0,6$ & $1,2-1,6$ \\
\hline Fosfatos & $1,0-3,0$ & $2,0-4,5$ \\
\hline Lactato & 2,0 & 6,4 \\
\hline Cloruros & 1,1 & 1,1 \\
\hline
\end{tabular}

Fuente: Panesar et al. ( 2007)

En cualquiera de los dos tipos de lactosuero obtenidos, se estima que por cada $1.0 \mathrm{~kg}$ de queso se producen $9.0 \mathrm{~kg}$ de lactosuero, esto representa 
cerca del $85-90 \%$ del volumen de la leche y contiene aproximadamente el $55 \%$ de sus nutrientes (Parra, 2009). Entre los más abundantes de estos nutrientes están la lactosa $(4,5-5 \% \mathrm{p} / \mathrm{v})$, proteínas solubles $(0,6-0,8 \% \mathrm{p} / \mathrm{v})$, lípidos $(0,4-0,5 \% \mathrm{p} / \mathrm{v})$ y sales minerales (8-10\% de extracto seco) (Londoño, 2006). Presenta una cantidad rica de minerales donde sobresale el potasio, seguido del calcio, fósforo, sodio y magnesio. Cuenta también con vitaminas del grupo B (tiamina, ácido pantoténico, riboflavina, piridoxina, ácido nicotínico, cobalamina) y ácido ascórbico (Londoño et al., 2008).

Además el lactosuero representa una rica y variada mezcla de proteínas secretadas que poseen amplio rango de propiedades químicas, físicas y funcionales (Foegeding \& Luck, 2002). Concretamente, suponen alrededor del $20 \%$ de las proteínas de la leche de bovino (Baro et al., 2001), siendo su principal componente la $\beta$-lactoglobulina ( $\beta$-LG) con cerca de $10 \%$ y $\alpha$-lactoalbúmina con $4 \%$ de toda la proteína láctea (Hinrichs et al., 2004), además, contiene otras proteínas como lactoferrina, lactoperoxidasa, inmunogiobulinas, y glicomacropéptidos (Baro et al., 2001). La $\beta$-LG es secretada en leches de rumiantes con alta resistencia a la digestión gástrica, lo que origina intolerancia y/o alergenicidad en seres humanos, a pesar de esto hoy en día se están desarrollando investigaciones encaminadas a la caracterización de los diferentes tipos de alimentos con proteína de suero de leche por medio de resonancia magnética nuclear de baja resolución (Hinrichs et al., 2004), igualmente se está trabajando en los tratamientos industriales como esterilización, calentamiento o presión hidrostática afta y la hidrólisis que mejoran la digestibilidad de la $\beta$-LG presente en el lactosuero (Pescumma et al., 2008).

\section{Procesos que intervienen en la obtención del lactosuero}

Físicamente, el fenómeno de la coagulación de la leche se traduce en la floculación de las micelas de caseína, que se sueltan para formar un gel compacto aprisionando el líquido de dispersión que constituye el lactosuero. Para realizar esta floculación las industrias queseras emplean diversos métodos pero los más utilizados son: coagulación ácida, coagulación enzimática y coagulación mixta (Badillo \& Solano, 2004).

La coagulación ácida se realiza de dos maneras: una natural y la otra inducida. La primera (acidez natural) consiste en dejar la leche en reposo para que las bacterias acido-lácticas presentes en la leche degraden la lactosa para formar ácido láctico; la segunda, en la adición de un ácido orgánico. Con ambos tratamientos se logra reducir el pH de la leche, provocando la alteración de las micelas de caseína y modificando su dispersabilidad. Cuando el pH de la leche llega a 5.2, las micelas se han desestabilizado produciéndose con esto la aglomeración y respectivamente el denominado gel láctico (Lucey, 2010).

La coagulación enzimática es el sistema de coagulación más utilizado en las industrias queseras, (Ruettimann \& Ladisch, 1991), la enzima provoca una proteólisis limitada de la caseína k con la cual pierde sus propiedades estabilizantes en presencia de calcio respecto a las caseínas y las micelas de caseínas, cuya estructura se ha modificado, uniéndose en flóculos y después en fibras que finalmente constituyen una red tridimensional cuya estructura se elabora progresivamente. La red retiene en su interior el lactosuero y los glóbulos grasos, de modo semejante a un líquido que impregna una esponja. La rigidez del gel está asegurada principalmente por el fosfato de calcio coloidal que constituye una verdadera armadura. La caseína se encuentra en forma de un complejo de fosfoparacaseinato de calcio, es decir una forma muy mineralizada. Los puentes de calcio y fosfato cálcico coloidal subsisten e incluso probablemente se encuentren reformados con relación a los presentes en el complejo nativo (Lucey, 2002).

En este tratamiento la coagulación mixta de la leche se hizo por acción conjunta del cuajo y la acidificación, con predominio de una u otra según los casos. En esta coagulación mixta se obtiene 
una cuajada con propiedades intermedias, menos características que las de las cuajadas obtenidas por un único método de coagulación (Badillo \& Solano, 2004).

Utilizado solo, el troceado es el modo de acción menos brutal, cuyo primer objetivo es la ruptura de la película, casi impermeable, que se forma en la superficie de las curvas de coagulación por la asociación de algunos de los componentes de la leche pertenecientes principalmente a la fase grasa (Badillo \& Solano, 2004).

A menudo, el troceado va seguido de la agitación de los granos más o menos acentuado y prolongado según los casos. La operación tiene por objeto "acelerar y completar" el desuerado, renovando continuamente la superficie de exudación de suero e impidiendo la adherencia de los granos, con los que se formaría un amasijo que retiene el líquido (Badillo \& Solano, 2004).

El lavado de los granos se realiza en salmuera poco concentrada. Esta operación tiene por objetivo diluir los componentes solubles del cuajo, fundamentalmente la capa de suero que cubre la superficie de granos de cuajada.

Entre los componentes solubles extraídos se encuentra la lactosa. Una cuajada lavada presenta, tras el desuerado un contenido relativamente bajo en lactosa. Por lo tanto, sus posibilidades de acidificación son reducidas (Badillo \& Solano, 2004).

El prensado de la cuajada tiene por objetivo completar el desuerado en numerosos procedimientos de fabricación, principalmente en los que se efectúa un troceado seguido del batido de la cuajada. La función del prensado es doble: completar el desuerado al forzar la eliminación del lactosuero y conferir al queso su forma definitiva. La velocidad de evacuación del lactosuero, su aspecto y acidez, son parámetros estrechamente ligados que determinan la calidad del producto (Badillo \& Solano, 2004).
Efectos contaminantes del lactosuero. El lactosuero constituye una importante fuente de contaminación ambiental debido al alto contenido de materia orgánica, lo cual expresado como DBO (demanda biológica de oxigeno) está entre 30.000 y $50.000 \mathrm{mg} / \mathrm{L}$ y como DQO (demanda química de oxigeno) entre 60.000 y 80.000 (Ávila, Cárdenas \& Medina, 2000). Además cerca del $90 \%$ de esta carga es aportada por el contenido de lactosa, la cual posee un tipo de enlace entre sus azúcares componentes que hace que muchos microorganismos no sean capaces de degradarla (Berruga, Jaspe \& San José, 1997). El vertimiento del lactosuero en fuentes hídricas hace que el agua se quede sin oxígeno, debido a la acción microbiana que transforma la materia orgánica en compuestos que disminuyen el $\mathrm{pH}$ del agua trayendo como consecuencia la producción de malos olores y la muerte de los organismos acuáticos que allí se encuentren (Londoño et al., 2008).

Este alto contenido de materia orgánica sumado al gran volumen de generación de lactosuero, que anualmente se incrementa en cerca del $3 \%$, y también la incapacidad de las pequeñas y medianas empresas lácteas de aprovechar el lactosuero de una manera rentable, ocasionan que cerca del $50 \%$ de la producción mundial sea desechada como efluente a los recursos hídricos o a los sistemas de alcantarillado sin ningún tratamiento, lo que ubica al desecho de este material como una amenaza considerable para el medio ambiente (Berruga, Jaspe \& San José, 1997).

\section{Usos del lactosuero en la industria alimentaria.}

Existe una serie de productos obtenidos del lactosuero de gran aceptación debido a sus bajos costos de producción, grado de calidad alimenticia y aceptable sabor, entre estos se encuentran:

Etanol. La producción de una bebida alcohólica por conversión del lactosuero es una alternativa de gran interés para la utilización de este subproducto industrial (Dragone et al., 2008). 
Destilerías de lactosuero están en operación en Irlanda, Nueva Zelanda, y los Estados Unidos. En la fermentación se emplea Kluyveromyces marxianus var. o Kluyveromyces fragilis y lactosuero desproteinizado como sustrato (Dragone et al., 2008). El proceso puede ser operado bajo condiciones asépticas usando lactosuero pasterizado, con temperatura de fermentación entre 24$34^{\circ} \mathrm{C}$ (Mawson, 2003). Este proceso fermentativo origina un rendimiento de etanol en un rango de 75- $85 \%$ del valor teórico, partiendo que por cada $0,538 \mathrm{~kg}$ de etanol se necesita de $1 \mathrm{~kg}$ de lactosa metabolizada, esto refleja la importancia en la producción de etanol que tiene el lactosuero.

Según Chacón, (2004) la biomasa puede ofrecer una alternativa para reemplazar algunas de las fuentes tradicionales de proteínas (soya, harina de pescado, suero descremado de leche etc.) en piensos para consumo animal e incluso en porciones para humanos después de ser tratado adecuadamente.

Las proteínas son usadas en una variedad de alimentos gracias a sus propiedades gelificantes y emulsificantes, siendo la $\otimes$-lactoglobulina el principal agente gelificante (Parra, 2009). Los geles de proteínas de lactosuero pueden ser usados como hidrogeles de $\mathrm{pH}$-sensitivos, el cual es una red tridimensional que muestra la habilidad de hincharse en agua y retiene una fracción significante de agua dentro de esta estructura (Gunasekaran et al., 2006).

La biomasa de levadura ha sido producida comercialmente desde 1940. Actualmente la producción de proteína es insuficiente para la alimentación y una alternativa a este problema es la producción de proteína de levadura a través de procesos de fermentación (Cori et al., 2006). Estos procesos pueden usar fuentes de carbono económicos como lactosuero, en el cual se puede utilizar Kluyveromyces lactis, un excelente microorganismo para producir biomasa y por lo tanto proteína de levadura (Castellón \& Ustariz, 2012).
Este proceso puede ser descrito como una reacción bioquímica de células y lactosa para producir células microbianas (biomasa) como principal producto (Ghaly \& Kamal, 2004). Al respecto Cori et al. (2006) obtuvieron y caracterizaron concentrados proteicos a partir de biomasa a través de la inoculación con Kluyveromyces marxianus con sulfato de amonio $0,2 \% \mathrm{p} / \mathrm{v}$, y extracto de levadura $0,1 \% \mathrm{p} / \mathrm{v}$ en un medio de fermentación que contenía el lactosuero, al final del estudio se obtuvieron valores de biomasa 4,65 g/L, también, Revillion, Brandelli \& Ayub (2003) utilizaron lactosuero en polvo inoculado con Kluyveromyces marxianus logrando una velocidad máxima de crecimiento específico de 0.62 h"1 y obteniéndose así mismo $26 \mathrm{~g} / \mathrm{L}$ de biomasa. Se puede analizar que el sustrato utilizado sin suplementación produce gran cantidad de biomasa comparado con el sustrato suplementado, es decir el sustrato contiene los requerimientos necesarios para producir altas concentraciones de biomasa.

El alto contenido de proteína en la biomasa microbiana determinaría su uso potencial en la alimentación humana y animal, ya que actualmente las fuentes convencionales como la agricultura, ganadería y pesca no satisfacen la demanda de alimento, situación que se ve agravada por el incremento alarmante de la población mundial (Páez et al., 2008). Además a partir de la biomasa pueden desarrollarse muchos productos derivados dada la riqueza de su composición: carbohidratos, lípidos, proteínas, ácido ribonucleico, vitaminas, etc. (Chacón, 2004).

Díaz, Semprun \& Gualtieri (2003), utilizaron residuos de vinaza como sustrato con la levadura Candida utilis suplementado con sulfato de amonio, urea y extracto de malta obteniendo 2,2 x108 células $/ \mathrm{ml}$, y en estudios similares Ghaly \& Kamal (2004) emplearon Kluyveromyces fragilis utilizando el lactosuero como medio de fermentación, suplementándolo con extracto de levadura $1 \%, 2 \%$ peptona, $2 \%$ de dextrosa, dando como resultado $8,5 \times 108$ células $/ \mathrm{ml}$. De lo anterior se puede decir 
que las diferentes formulaciones pueden aumentar la biomasa dependiendo del microorganismo y la composición del medio, además de otros factores.

El lactosuero en polvo es bien conocido como ingrediente en la industria de la panificación por resaltar su sabor y cualidades de calidad. Volumen, textura, corteza y retención de frescura en el pan de trigo, estas características son proporcionadas por la incorporación de una combinación de emulsificantes y lactosuero en polvo (Biocity, 2004).

Dos procesos han sido desarrollados en la producción de levaduras destinadas a la panificación, en el primero la lactosa es hidrolizada utilizando $\beta$-galactosidasa, y la glucosa y galactosa son consumidas simultáneamente por la levadura. El segundo proceso utiliza un sistema de fermentación de dos etapas. En el estado inicial, las bacterias ácido lácticas convierten lactosa a lactato y este es consumido en la segunda etapa por la levadura. Finalmente, la biomasa puede ser degradada mecánicamente o biológicamente para eliminar componentes celulares los cuales pueden purificar o transformarse a productos de alto valor (Parra, 2009).

Diferentes ácidos orgánicos pueden ser obtenidos a través de la fermentación de lactosuero, entre estos se tienen, butírico, propiónico y acético los cuales representan una posibilidad para la utilización de lactosuero como sustrato (Parra, 2009).

Durante la fermentación del lactosuero, el etanol puede ser además metabolizado a ácido acético por Acetobacter spp. El ácido acético es producido a partir de la fermentación anaerobia de lactosa por cultivos de Streptococcus lactis y Clostridium formicoaceticum a $35^{\circ} \mathrm{C}$ y $\mathrm{pH}$ entre 7,0 y 7,6 , la lactosa fue convertida a ácido láctico, ácido acético. El rendimiento total de ácido acético a partir de lactosa fue cerca de $95 \%$ a pH 7,6 y $90 \%$ a pH 7,0. En la fermentación en lote de lactosuero permeado conteniendo cerca de 5\% de lactosa a pH 7,6, la concentración de ácido acético alcanzó $20 \mathrm{~g} / \mathrm{L}$ en menos de 20 horas (Tang, Yang \& Okos, 1988).
El ácido propiónico ha sido muy utilizado en industrias químicas, de alimentos y farmacéuticas, en la industria alimenticia es añadido como un agente fungistático a productos de panadería. Normalmente, casi todo el ácido propiónico es elaborado por síntesis química, sin embargo se puede obtener a través de fermentación de la lactosa del lactosuero por Propionibacterium acidipropionici, Propionibacterium freudenreichii spp. Shermanii, y Lactobacillus helveticus a condiciones de fermentación de $30^{\circ} \mathrm{C}$ y pH 6.5-7.5. Suplementos como extracto de levadura, y lactosa realzan considerablemente la producción de propionato y un rendimiento cercano de $40 \%$ de lactosa fermentada es lograda después 60-70 horas de fermentación (Parra, 2009).

El lactosuero ha sido un medio de cultivo para la producción de ácido láctico por vía biotecnológica (Ghasemi, et al., 2009). La fermentación láctica ha sido típicamente conducida en modo batch utilizando cepas homofermentativas de Lactobacillus delbrueckii spp. Bulgaricus, y Lactobacillus casei, donde fuentes de complejos nutricionales como licor de maíz, malta o extracto de levadura pueden ser suplementados al medio (Parra, 2009).

La fermentación de lactosuero por bacterias ácido lácticas podría disminuir el contenido de lactosa, produciendo principalmente ácido láctico y otros metabolitos, como componentes aromáticos que contribuyen al sabor y textura e incrementan la solubilidad de carbohidratos y el dulzor final del producto (Pescumma et al., 2008).

Recientemente se están desarrollando investigaciones encaminadas a que los desechos de la industria quesera, sean capaces de combatir bacterias, lo que consiste en fermentar el suero de quesería con gránulos de kefir (mezcla de bacterias y levaduras). Se observó que el producto obtenido tenía una gran capacidad bactericida. Por ejemplo, los patógenos como Salmonella y Escherichia coli, que suelen contaminar alimentos, perdían por completo su viabilidad al ser expuestos a este 
nuevo producto. Los gránulos de kefir tienen un aspecto similar al de las flores del coliflor y están compuestos por bacterias y levaduras probióticas (microorganismos que producen efectos beneficiosos sobre el organismo), proteínas y polisacáridos. Estos gránulos fermentan el suero de leche y se produce el ácido láctico, entre otros metabolitos, que es el principal agente inhibidor de las bacterias contaminantes (Garrote, 2012).

Hoy en día, los quesos son elaborados considerando su consumo, preservación, versatilidad, conveniencia y reducción de costos. Con los avances en la tecnología de lácteos, nuevos ingredientes como leche en polvo, lactosuero en forma de polvo o concentrados de proteína de lactosuero (WPC) están ahora disponibles para la incorporación dentro del procesamiento del queso (Angulo, 2005).

La adición de lactosuero en la elaboración de quesos es limitada, al agregar la proteína coagulada o en forma de concentrado se obtuvo un aumento en el rendimiento, y originó alteraciones importantes en la textura, cuerpo y contenido de humedad, como se ha podido demostrar en investigaciones llevadas a cabo en queso Cheddar (Parra, 2009).

A diferentes tipos de quesos madurados han sido añadidos WPC con diferentes rendimientos, por ejemplo: queso tipo Camembert añadiéndose 1\% de WPC, se ha obtenido un rendimiento de $30 \%$, queso Saint-Paulin al cual se le añadió $5,56 \%$ de proteína se obtuvo $12 \%$ de rendimiento, queso suave tipo Camembert con $1 \%$ de WPC se obtuvo rendimiento máximo de 30\% (Parra, 2009).

El lactosuero desproteinizado o completo puede ser fermentado para producir una gama de bebidas de suero de leche (Holsinger, Posati \& DeVilbiss, 1974). La principal ventaja ofrecida por el lactosuero como sustrato para la producción es que estas bebidas tienen un gran valor nutritivo, rehidratan y son menos ácidas que los jugos de frutas. La comercialización de estos productos generalmente enfatiza en la salud y beneficios nutricionales, especialmente si ellas aun contienen las proteínas de lactosuero (Bourgeois \& Larpent, 1989). Una variedad de bebidas de este subproducto están disponibles en algunos países, aunque ellas son más populares en Europa, representan un sector emergente de productos lácteos no convencionales que requieren características sensoriales, físicas y químicas para el control de calidad y desarrollo del producto (Mawson, 2003). Levaduras y BAL coexisten en una asociación simbiótica y son responsables para una fermentación ácido-láctica. Esta mezcla de cultivo es capaz de utilizar lactosa de los subproductos lácteos como material para la producción de kéfir y para la liberación de microorganismos probióticos en el intestino del humano (Parra, 2009).

Londoño et al (2008) realizaron una bebida fermentada basada en lactosuero como sustrato, se inoculó con Lactobacillus delbrueckii, LactobaciIlus casei y Streptococcus salivarius, una mezcla de sacarosa, jarabe de azúcar invertido, carboxímetilceiulosa y crema de leche, al final se tuvo un nivel de aceptación bueno de la bebida, de igual manera, Gauche et al (2009) añadieron 20\% de lactosuero al yogurt, presentando características similares al yogurt elaborado tradicionalmente.

González et al. (2002) estudiaron la aplicación de WPC en la elaboración de yogurt utilizando leche en polvo descremada y caseinato de sodio; el tiempo de fermentación disminuyó con el incremento de los niveles de suplementación de caseinato sódico. Un efecto opuesto fue observado cuando se suplemento con leche en polvo descremada y no hubo cambios cuando se añadió WPC entre 0,6 y $4 \%$.

Otros productos. Durante la elaboración de queso casi toda la lactosa de la leche es transferida al lactosuero, es un importante producto de la industria láctea y su demanda global ha crecido apreciablemente en los últimos 10 años a una cantidad aproximadamente de 500.000 t por año (Jelen, 
2003). Debido al bajo valor comercial de la lactosa, y la solubilidad baja e intolerancia presentada por algunas personas, nuevos aprovechamientos han sido propuestos para la derivación de lactosa y nuevos usos para estos derivados (Lopes et al., 2007), dentro de estos están galletas, bizcochos, chocolate, azúcar para confites, sopas, salsas y alimentos para bebes, por su poder endulzante. Esta lactosa se puede obtener de diferente grado de pureza como cruda, comestible o grado farmacéutico según sea su aplicación (Bund \& Pandit, 2007).

La producción de enzimas es una área importante en la utilización de proteínas lácteas para acelerar la maduración de queso, se emplean aminopeptidasas que son obtenidas a partir de la fermentación de lactosuero (Choi et al., 1996), también la producción de $\alpha$-amilasa usando cepas de Baciilus subtilis, está influenciada por la naturaleza de las fuentes de concentración de carbono y nitrógeno produciendo grandes concentraciones de enzima en un medio que contenga lactosa. La $\beta$-galactosidasa o lactasa puede ser producida y caracterizada a partir de cepas de Kluyveromyces lactis propagada en suero de leche desproteinizado (Ramírez \& Rivas, 2003). La $\beta$-galactosidasa puede ser usada para hidrolizar la lactosa o solucionar el problema de la intolerancia a la lactosa al generar jarabes para uso alimentario (Linden \& Lorient, 1996).

Las bacterias ácido lácticas, y específicamente las producciones de bacteriocinas, son exigentes debido a la necesidad de enriquecer el medio de crecimiento, conteniendo nutrientes como carbohidratos, ácidos nucleicos, minerales, vitaminas, y principalmente aminoácidos, proteínas o hidrolizados de proteínas (Fernandes et al., 2009). Por ejemplo, los medios de laboratorio estándar (MRS, TGE, APT) solucionan el problema de fuentes de proteína, incorporando productos como bactopeptona, triptófano, extracto de carne o extracto de levadura en formulaciones las cuales alcanzan costos altos (Vásquez \& Murado, 2008). Sin embargo el lactosuero se ha utilizado como medio de fermentación para la obtención de bacteriocinas por ser económica y de gran potencial nutritivo (Gómez \& García, 2003).

\section{Conclusiones}

Los grandes problemas ambientales asociados al sector lácteo tienen relación básicamente con los residuos líquidos y sólidos. Los residuos sólidos generados en el proceso productivo, la mayoría pueden ser reciclados hacia otros sectores industriales; mientras que los líquidos generados en la planta de tratamiento usualmente son dispuestos en vertederos o reutilizados como abono, por lo tanto el lactosuero puede presentar importantes alternativas de uso gracias a su aprovechamiento ya que se puede obtener producto de alto valor agregado que además presenta una alta demanda entre los consumidores, así mismo este subproducto representa una rica y variada mezcla de proteínas secretadas que poseen amplio rango de propiedades químicas, físicas y funcionales para el sector agroalimentario.

De esta manera, se generará un estímulo y una forma de plantearlo como una alternativa de inversión sustentable para los empresarios. Así se lograría un resultado efectivo para ayudar al medio ambiente y a las empresas, contribuyendo de esta forma al beneficio entre ambas partes al reutilizar este subproducto, pues se cambiaría el enfoque que actualmente tiene el lactosuero como un problema inevitable de contaminación y se vería como una fuente de generación de riqueza. Igualmente esta biomasa tiene diversos usos y en especial la de potenciar la extracción de la enzima B-galactosidasa que es un producto de alto valor agregado, así como la producción de concentrados para consumo animal o como fuente proteica en general, ya que el perfil de aminoácidos de las proteínas de esta levadura presenta una distribución equilibrada, comparada con los patrones de la FAO. 


\section{Literatura citada}

1. Ariza C, J. \& Franco G, J. (2006). Mejoramiento de dietas líquidas a partir del lactosuero inoculado con el micelio Geotrihum sp para ceba de cerdos. Trabajo de grado de Ingeniería agroindustrial. Valledupar: Universidad Popular del Cesar.

2. Almécija, M. C. (2007). Obtención de la lactoferrina bovina mediante ultrafiltración de lactosuero. Tesis de Doctorado en Tecnología y Calidad de los Alimentos. Facultad de Química. Granada: Universidad de Granada.

3. Angulo, C. R. (2005). Factibilidad de producción y estudio de rendimiento de queso chanco con incorporación de suero en polvo. Tesis de Maestría en Ciencias y Tecnología de la Leche. Valdivia: Universidad Austral de Chile.

4. Ávila, R., Cárdenas, A. \& Medina, A. (2000). Tratamiento del lactosuero utilizando la técnica de hemodiálisis. Interciencia 25 (2): 80-84.

5. Badillo, L. \& Solano, M. (2004). Aprovechamiento del lactosuero como medio de cultivo para el crecimiento de hongos (Rhodotorula sp, Saccharomyces cerevisiae, Geotrichum candidum) Trabajo de grado en Ingeniería agroindustrial. Valledupar: Universidad Popular del Cesar.

6. Baro, L., Jiménez, J., Martínez, A. \& Bouza, J. (2001). Péptidos y proteínas de la leche con propiedades funcionales. Ars. Pharmaceutica. 42 (4): 135-145.

7. Berruga, m. I., Jaspe, A. \& San Jose, C. (1997). Sellection of yeast strains for lactose hydrolysis in dairy effluents. International Biodeterioration \& Biodegradation. 40 (4): 119-123.

8. Biocity. (2004). Levaduras. Disponible en: http: // biocity. iespaña.es./biocity/micro/leva.htm. (Consultado en 27 de abril de 2012).

9. Bourgeois, C. M. \& Larpent, J. (1989). Microbiología alimentaria. Fermentaciones alimentarias. Vol. 2. Zaragoza: Editorial Acribia.

10. Bund, R. \& Pandit, A. (2007). Rapid lactose recovery from buffalo whey by use of anti-solvent, ethanol. Journal of Food Engineering. 82 (3): 333-341.

11. Castellón, P. E. \& Ustariz, N. G. (2012). Evaluación del crecimiento in vitro de Kluyveromyces marxianus en lactosuero dulce de queserías en la ciudad de Valledupar. Trabajo de grado en Ingeniería agroindustrial. Valledupar: Universidad Popular del Cesar.

12. Chacón, A. (2004). Perspectivas actuales de la proteína celular en la agricultura y la industria. Revista de Agronomía Mesoamericana. 15 (1): 93-106.

13. Choi, H., Laleye. L., Amantea, G. \& Simard, R. (1996). Production of aminopeptidase from skim milk whey permeates medium by Lactobacillus casei sp. Journal of Dairy Science. 79 (6): 956-963.

14. Cori, M., Rivas, N., Dorta, B., Pacheco, E. \& Bertsch, A. (2006). Obtención y caracterización de dos concentrados proteicos a partir de biomasa de Kluyveromyces marxianus var. marxianus cultivada en suero lácteo desproteinizado. Revista Científica (Maracaibo). 16(3): 315-324.
15. de Palma, J., Brandelli, A. \& Zachia, M. (2003). Production of yeast extract from whey using Kluyveromyces marxianus. Brazilian Archives of Biology and Technology. 46 (1): 121-127.

16. Departamento Técnico Administrativo del Medio Ambiente. (DAMA). (2003). Programa de Tasas Retributivas. Ley/1993/ley_0099_

17. Díaz, M., Semprun, A. \& Gualtieri, M. (2003). Producción de Proteína celular a partir de desechos de vinaza. Revista de la Facultad de Farmacia. 45 (2): 23-26.

18. Dragone, G., Mussatto, S., Oliveira, J. \& Teixeira, J. (2008). Characterization of volatile compounds in analcoholic beverage produced by whey fermentation. Food Chemistry. 112 (4): 926-935

19. Fernandez, M., R. Fornari, M. Mazutti, D. Oliveira, F. Ferreira, A. Cichoski, R. Cansian, M. Luccio \& Treichel, $H$. (2009). Production and characterization of xantham gum by Xanthomonas campestris using cheese whey as sole carbon source. Journal of Food Engineering. 90(1): 119-123.

20. Foegeding, E. \& Luck,P. (2002). Whey protein products. 1957-1960. In: Caballero, B., L. Trugo, P. Finglas (eds.). Encyclopedia of Foods Sciences and Nutrition. New York: Academic Press.

21. Garrote, G. (2012). Desechos de la industria quesera, capaces de combatir bacterias. Journal of Food Protection. Disponible en: www.docsalud.com/articulo/194. (Consultado en 27 de abril de 2013).

22. Gauche, C., Tomazi, T., Barreto, P., Ogliari, P. \& Bordignon, M. (2009). Physical properties of yogurt manufactured with milk whey and transglutaminase. LWT- Food Science and tecnology. 42(1): 239-243.

23. Ghaly, A. \& Kamal, M. (2004). Submerged yeast fermentation of acid chesse whey for protein production and pollution potencial reduction. Water Research. 38 (3): 631-644.

24. Ghasemi, M., Najafpour, G., Rahimnejad, M., Aeineh, P., Sedighi, M. \& Hashemiyeh, B. (2009). Effect of different media on production of lactic acid from whey by Lactobacillus bulgaricus. African Journal of Biotechnology. 8(1): 081-084.

25. Gil, K.A., Najul, M. V. \& Pacheco, C. (2003). Manejo de desperdicios en industrias de derivados lácteos con criterios competitivos. Trabajo Especial de Grado. Caracas: Universidad Central de Venezuela.

26. Gómez, M. \& García, C. (2003). X Congreso sociedad Mexicana de Biotecnología y Bioingeniería por Lactococcus lactis UQ2. En Memorias: X Congreso de la Sociedad Mexicana de Biotecnología y Bioingeniería. Puerto Vallarta: México.

27. González, C., Becerra, M., Cháfer, M., Albors, A., Carot, J. \& Chiralt, A. (2002). Influence of substituting milk powder for whey powder on yoghurt quality. Trends in Food Science \& Technology. 13 (9-10): 334-340. 
28. Gunasekaran, S., Ko, S. \& Xiao, L. (2006). Use of whey proteins for encapsulation and controlled delivery applications. Journal of Food Engineering. 83(1): 31- 40.

29. Heden, C.G. \& Enebo, L. (1969). The Potential of microbiol food resources. International Botany Congress, II th Seattle, USA. (abstract).

30. Hinrichs, R., Götz, J., Noll, M., Wolfschoon, A., Eibel, H. \& Weisser, H. (2004). Characterization of different treated whey protein concentrate by means of low resolution nuclear magnetic resonance. International Dairy Journal. 14 (9): 817-827

31. Holsinger, V. H., L. P. Posati, \& DeVilbiss, E.D. (1974). Whey beverages: A review. J. Dairy Sci. 57:849.

32. Huertas, P. A. (2009). Lactosuero: importancia en la industria de alimentos. Rev. Fac.Nal. Agr. Medellín 62 (1): 4967-4982.

33. Inda, A. (2000). Optimización de rendimiento y aseguramiento de inocuidad en la industria de quesería. México: Editorial Organización de los Estados Americanos.

34. Jelen, P. (2003). Whey processing. Utilization and Products. In: H. Roginski, J.W. Fuquay and P.F. Fox (eds.). 2739-2745. Encyclopedia of Dairy Sciences. London: Academic Press.

35. Koutinas, A., Papapostolou, H. Dimitrellou, D., Kopsahelis, N., Katechaki, E., Bekatorou, A. \& Bosnea, L. (2009). Whey valorisation: A complete and novel technology development for dairy industry starter culture production. Bioresource Technology. 100 (15): 37343739.

36. Linden, G. \& Lorient, D. (1996). Bioquímica Agroindustrial: revalorización alimentaria de la Producción agrícola. Editorial Acribia, Zaragoza. España. 454 p.

37. Londoño, M. (2006). Aprovechamiento del suero ácido de queso doble crema para la elaboración de quesillo utilizando tres métodos de complementación de acidez con tres ácidos orgánicos. Perspectivas en Nutrición Humana. 16: 11-20.

38. Londoño, M., Sepúlveda, J., Hernández, A. \& Parra, J. (2008). Bebida fermentada de suero de queso fresco inoculado con Lactobacillus casei. Revista Facultad Nacional de Agronomía. 6 (1): 1110-1114.

39. Lopes, M., Saron, C., Lerayer, A. \& Sgarbieri, V. (2007). Use of bovine whey permeate and lactulose as potencial enhancers of the MRS and modified MRS media for the cultivation of species of probiotico bacteria. Braz. J. Food Technol.10 (19): 53-41.
40. Lucey, J.A. (2010). Formation and physical properties of yogurt. Asian-Aust. J. Anim. Sci. Vol. 23, N. ${ }^{\circ}$ 9, 1127-1136.

41. Lucey, J.A. (2002). ADSA Foundation Scholar Award. Formation and Physical Properties of Milk Protein Gels. J. Dairy Sci. 85, 281-294.

42. Mawson., J. (2003). Fermentation of whey. In: Caballero, B. (ed.). Encyclopedia of Food Sciences and Nutrition. 6157-6163. London: Academic Press.

43. Muñi, A., Paez, G., Faría, J., Ferrer, J. \& Ramones, E. (2005). Eficiencia de un sistema de ultrafiltración/ nanofiltración tangencial en serie para el fraccionamiento y concentración del lactosuero. Revista Científica 15 (4): 361-367.

44. Páez., G., Jiménez, E., Mármol, Z., Sulbarán, B., Ojeda, G., Araujo, K. \& Rincón, M. (2008). Perfil de aminoácidos de la proteína unicelular de Kluyveromyces marxianus var. marxianus. Interciencia. 33 (1): 1-14.

45. Panesar, P., Kennedy, J., Gandhi, D. \& Bunko, K. (2007). Bioutilisation of whey for lactic acid production. Food Chemistry. 105: 1-14.

46. Parra, A. (2009). Lactosuero: importancia en la industria de alimentos. Revista Facultad Nacional de Agronomía.62 (1): 4967-4982.

47. Pescumma, M., Herbet, E., Mozzi, F. \& font, G. (2008). Whey fermentation by thermophilic lactic acid bacteria: evolution of carbohydrates and protein content. Food Microbiology. 25 (3): 442-451.

48. Ramírez, M. A. \& Rivas, N. (2003). Producción y caracterización parcial de $\bigotimes$-galactosidasa de Kluyveromyces lactis propagada en suero de leche desproteinizado. Archivos Latinoamericanos de Nutrición. 53 (2): 194-201.

49. Ruettimann, K.W. \& Ladisch, M.R. (1991). In situ observation of casein micelles coagulation. J. Colloid Interface Sci. 146: 276-287.

50. Tang, I., Yang, S. \& Okos, M. (1988). Acetic acid production from whey lactose by the co-culture of Streptococcus lactis and Clostridium formicoaceticum. Applied Microbiology and Biotecnology. 28 (2): 138-143.

51. Vásquez, J. \& Murado, M. (2008). Enzymatic hydrolysate from food wastewater as a soure of peptones for lactic bacteria productions. Enzyme and Microbial Technology. 43 (1): 66-72.

52. Zumbado-Rivera, W., Esquivel-Rodríguez, P. \& WongGonzález, E. (2006). Selección de una levadura para la producción de biomasa: crecimiento en suero de queso. Agronomía Mesoamericana. 17 (2): 151-160. 